\title{
Pengendali Putaran Turbin Pltmh Menggunakan Arduino
}

\author{
Okta Andrica Putra \\ Universitas Putra Indonesia"YPTK" Padang \\ Email: okta.andrica@gmail.com
}

\begin{abstract}
Research has been carried out to regulate / control the rotation of the turbine for this type of micro hydro power plant (PLTMH). This research was carried out during the dry season where water discharge greatly affects turbine rotation. This tool utilizes an optocoupler sensor, servo motor and 2x16 LCD. This system works based on the turbine rotation speed that is read on the sensor then controls the slope of the water fall using a DC motor. If the water speed is low, the servo motor will turn $\mathrm{CW}$ up to a maximum slope of 75 degrees to produce maximum rotation and maximum power. This research does not focus on the magnitude of the resulting current source and the amount of water discharge.
\end{abstract}

Keywords: MHP, Optocoupler Sensor

\begin{abstract}
Abstrak
Telah dilakukan penelitian untuk mengatur/mengendalikan putaran turbin untuk jenis Pembangkit listrik micro hidro (PLTMH) penelitian ini dilakukan pada saat musim kemarau dimana debit air sangat berpengaruh terhadap perputaran turbin. Alat ini memanfaatkan sensor Optocoupler, motor servo dan LCD 2x16, Sistem ini bekerja berdasarkan kecepatan putaran turbin yang terbaca pada sensor kemudian dilakukna pengendalian kemiringan jatuhnya air menggunakan motor DC. Apabila kecepatan air rendah maka motor servo akan berputtar CW hingga kemiringan maksimal yaitu 75 derajat untuk bisa menghasilkan putaran maksimum dan daya maksimum. Penelitian ini tidak menitik beratkan kepada besarnya sumber arus yang dihasilkan dan besaran debit air.
\end{abstract}

Kata Kunci : PLTMH, Sensor Optocoupler

\section{Pendahuluan}

Arduino adalah papan modul mikrokontoller yang didalamnya tertanam sebuah sistem IC chip yaitu Arduino UNO yang bertindak sebagai komputer yang dapat menggontrol beberapa komponen elektronik secara komplek dan efisien. Arduino Uno jika diterapkan maka akan Dapat Membuat Sebuah Sistem Pengontrol, seperti Pengendalian putaran turbin PLTMH menggunakan Arduino Dengan menggunakan Sensor Optocoupler sebagai Pendeteksi putaran turbin dan motor Servo untuk mengatur kemiringan turbin PLTMH serta LCD 2x16 sebagai media informasi

\section{Metode Penelitian}

Dalam melakukan penelitian agar mendapatkan hasil seperti yang diinginkan, maka sekiranya diperlukan suatu metodologi penelitian yang umum dilakukan yaitu :

\section{Penelitian Laboratorium (Laboratory Research)}

Metode ini melakukan percobaan yang berupa perancangan, pembuatan, pengetesan dan pemecahan masalah yang bersifat teknik terhadap rangkaian, seperti komponen atau modul elektronika dan bahasa pemrograman. Peralatan yang akan digunakan yaitu :

Tabel 3.2 Spesifikasi Hardware dan Software

\begin{tabular}{l|l|l|} 
Hardware & Software & Tools \\
\hline
\end{tabular}




\begin{tabular}{|l|l|l|}
\hline Computer (PC) & SistemOperasi & Bor \\
dengan spesifikasi & Windows 7 & Obeng \\
$:$ Ultimate 32 Bit & Solder \\
a. Processor & Microsoft Office & Timah \\
Intel(R) & 2010 & \\
CoreTM i3- & Arduino 1.6.9 & \\
$2310 \mathrm{M}$ CPU & & \\
@ 2.10 GHz. & & \\
b. RAM 2.00 & & \\
GB & & \\
c. Hard disk 500 & \\
GB & & \\
Printer Canon IP & & \\
2770 & & \\
Modul Arduino & \\
Mega & & \\
\hline
\end{tabular}

\section{Penelitian Kepustakan (Library Research)}

Penelitian ini dilakukan dengan cara membaca buku-buku sebagai referensi yang berkaitan dengan penelitian ini di perpustakaan, yang berguna untuk memperoleh data dan informasi yang bersifat teoritis.

\section{Penelitian di Internet (Research On the Internet)}

Dengan membaca dan mencari referensi yang berkaitan dengan penelitian ini di dalam situs, jurnal maupun datasheet.

\section{Analisa Sistem}

Berdasarkan identifikasi masalah diatas, peneliti melakukan analisa data terlebih dahulu. Hal ini bertujuan agar pemecahan masalah dapat menghasilkan sebuah solusi yang baru. Pemanfaatan Arduino UNO, penggunaan sensor Optocoupler serta penambahan LCD 2x16 sebagai informasi

\section{Perancangan Sistem / Perancangan Alat}

Pada tahap ini akan membuat sebuah perancangan sistem yang akan dijalankan. Mulai dari menganalisa program yang sedang berjalan, merancang program yang akan dibangun guna menjalankan sistem yang akan dibuat menggunakan mikrokontroller Arduino UNO. Pada tahap ini juga dilakukan pengumpulan fakta-fakta yang mendukung perancangan sistem.

\section{Implementasi}

Implementasi sistem merupakan tahap meletakan sistem sehingga siap untuk digunakan. Implementasi bertujuan untuk mengkonfirmasi modul-modul perancangan sehingga pengguna dapat memberi masukan kepada pengembangan sistem. Pada tahap ini perancangan sistem dilakukan dengan menggunakan pemrograman Arduino (bahasa C).

\section{Analisa Dan Hasil}

Context diagram merupakan pendefenisian terhadap sistem yang akan dirancang yang bersifat menyeluruh. Context diagram berfungsi sebagai media, yang terdiri dari proses dan beberapa buah external entity. Context diagram yang dimaksud dapa dilihat pada gambar 4.1 


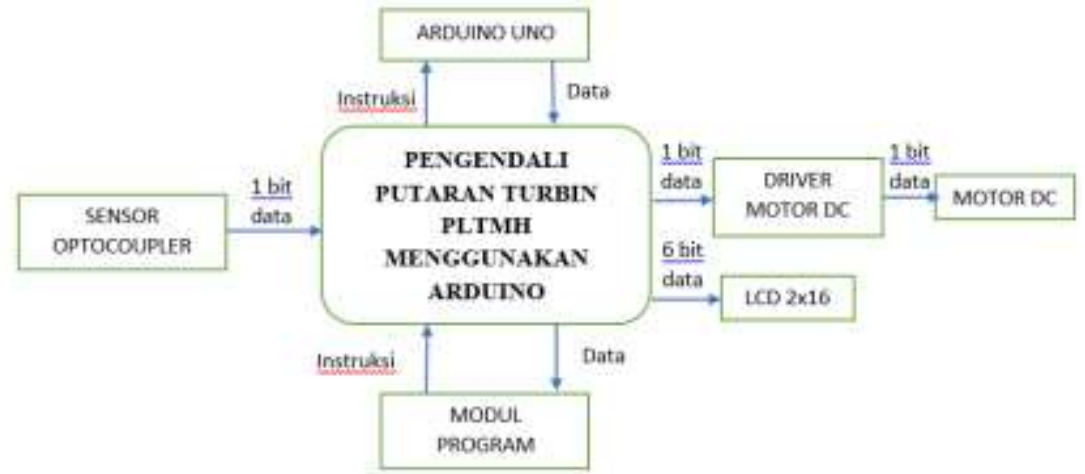

Gambar .1 Context diagram

Sistem ini berintraksi dengan beberapa entity yaitu Sensor Optocoupler Motor DC, Arduino UNO dan LCD 2x16. Entity-entitiy tersebut akan dijelaskan dibawah ini sebagai berikut:

1 Sensor Optocoupler

Berfungsi sebagai pendeteksi putaran dari turbin.

2 Arduino UNO

Berfungsi untuk memproses instruksi- instruksi yang di terima dari setiap modul.

3 Modul program

Melakukan pembacaan tehadap pin-pin mikrokontroler, baik pembacaan tehadap sinyal-sinyal input, memberikan instruksi-instruksi untuk untuk mengaktifkan pin-pin output. Modul program mengontrol semua prroses yang terjadi di arduino.

4 LCD $2 \times 16$

Berfungsi untuk menampilkan keterangan Kecepatan putaran pada turbin

5 Motor Servo

Digunakan untuk mengatur kemiringan turbin agar putaran tetap pada kondisi puncak meskipun jumlah debit air berkurang

\section{Data Flow Diagram}

Data flow diagaram merupakan suatu cara atau metode untuk membuat rancangan sebuah sistem yang mana berorientasi pada alur data yang bergerak pada sebuah sistem nantinya. DFD berfungsi menggambarkan suatu sistem yang telah ada atau sistem baru yang akan dikembangkan secara logika tanpa mempertimbangkan lingkungan fisik dimana data tersebut mengalir atau lingkungan fisik dimana data tersebut disimpan. DFD menggambarkan arus data didalam sistem dengan terstruktur dan jelas. DFD yang dimaksud dapat dilihat pada gambar 4.2.

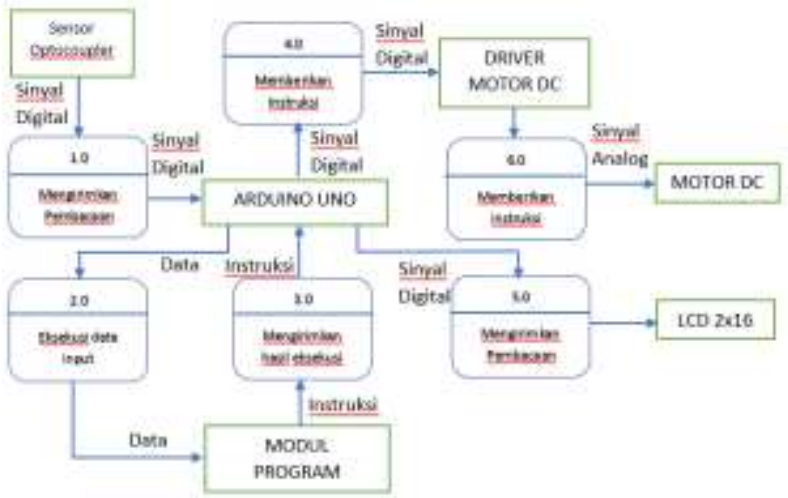

Gambar 2 Data Flow Diagram

Sistem ini berinteraksi dengan beberapa entity- entety yaitu Sensor Optocupler, Arduino modul program, driver motor dan motor dc. Entity-entity tersebut akan dijelaskan dibawah ini sebagai berikut : 
Sensor Optocupler membaca kecepatan dari pada turbin, nilai pembacaan tersebut dikirim ke Arduino untuk dieksekusi (1.0) setelah itu Arduino membaca nilai yang diberikan oleh sensor melalui modul program (2.0), modul program mengirimkan instruksi untuk dieksuki berdasarkan pengeturan PIN output pada Arduino (3.0) output dari eksekusi program adalah pengaturan kemiringan turbin menggunakan motor DC melalui driver(4.0). motor akan bergerak CW atau CCW berdasarkan input yang diberikan. LCD akan memberikan informasi debit air yang ada pada turbin.

\section{Blok Diagram}

Blok diagram digunakan untuk lebih menyerdehanakan pemahaman, dengan menjelaskan prinsip kerja alat secara keseluruhan yaitu berupa gabungan prinsip elektronika dan mekanika yang dikontrol oleh pemrograman, dapat dilihat pada gambar 4.3 berikut ini.

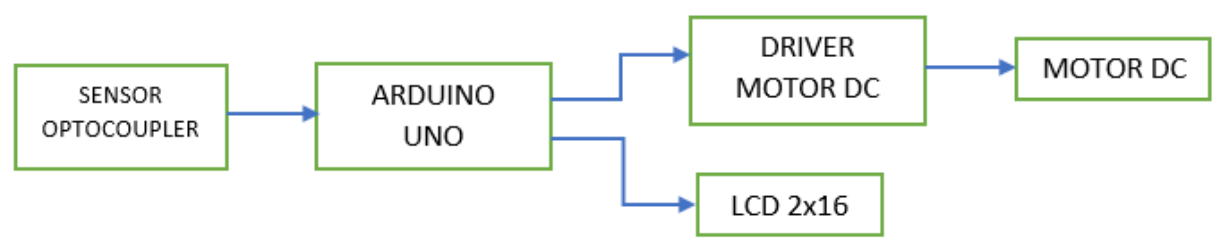

Gambar 3 Blok Diagram

Dari gambar block diagram diatas bahwa pusat pemrosesan dilakukan pada Arduino, sensor Optocoupler sebagai input, motor DC dan LCD sebagai output.

\section{Prinsip Kerja Sistem}

Cara kerja dari sistem Pengendali putaran turbin menggunakan Arduino ini dimulai ketika sensor Optocoupler membaca nilai putaran dari turbin, yang dikirimkan secara terus menerus. Nilai pembacaan ini akan diketegorikan berdasarkan jumlah debit air. Jika putaran turbin lambat, berarti debit air kurang. Jika putaran turbin kencang berarti debit air tinggi. Berdasarkan hal tersebut maka, pada saat debit air kurang dan putaran turbin lambat maka motor akan diinstruksikan untuk menurukan sudut kemiringan dari posisi turbin semula, dan jika debit air tinggi dan putaran turbin rendah maka motor akan menaikkan sudut kemiringan

\section{Rancangan Fisik Sistem}

Alat yang dibuat ini rancangan bangun dari sebuah miniatur mobil berukuran $100 \mathrm{~cm} \times 50 \mathrm{~cm}$ sebagai media pendinginan dalam ruangan mobil, gambar 4.4 Memperlihatkan rancangan fisik alat secara keseluruhan.

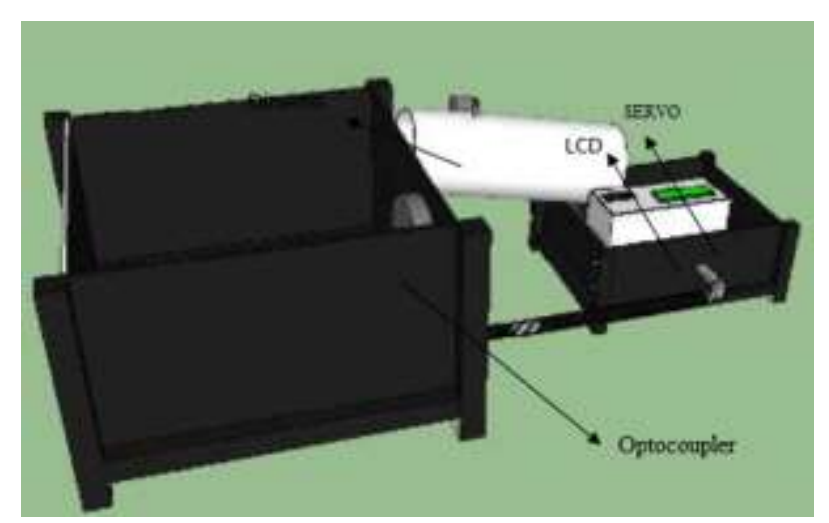

Gambar 4 Rancangan Fisik Alat Secara Keseluruhan

Pada gambar rancangan fisik alat, miniatur mobil berukuran $100 \mathrm{~cm}$ x $50 \mathrm{~cm}$ sebagai media pendinginan dalam ruangan mobil, terdapat sensor suhu DHT11 untuk mendeteksi panas dalam ruang mobil, 
kemudian lcd 16x2 yang berfungsi menampilkan hasil yang ditangkap oleh sensor DHT11, jika kondisi ruang mobil $>45^{\circ} \mathrm{C}$ maka peltier 2 akan hidup secara otomatis dan modul GSM mengirimkan notifikasi kepada user bahwa kondisi dalam ruang mobil sangat panas $>45^{\circ} \mathrm{C}$.apabila kondisi suhu dalam ruang mobil sudah berkurang atau $<45^{\circ} \mathrm{C}$ maka peltier 2 akan mati lalu peltier 1 tetap menyala untuk menstabilkan suhu ruang pada mobil tersebut.

\section{Flowchart}

Sistem ini dikendalikan sepenuhnya oleh mikrokontroler dengan bantuan sebuah aplikasi yang dirancang dengan logika bahasa pemrograman basic complier. Untuk lebih jelasnya logika program dapat dilihat pada gambar 4.5

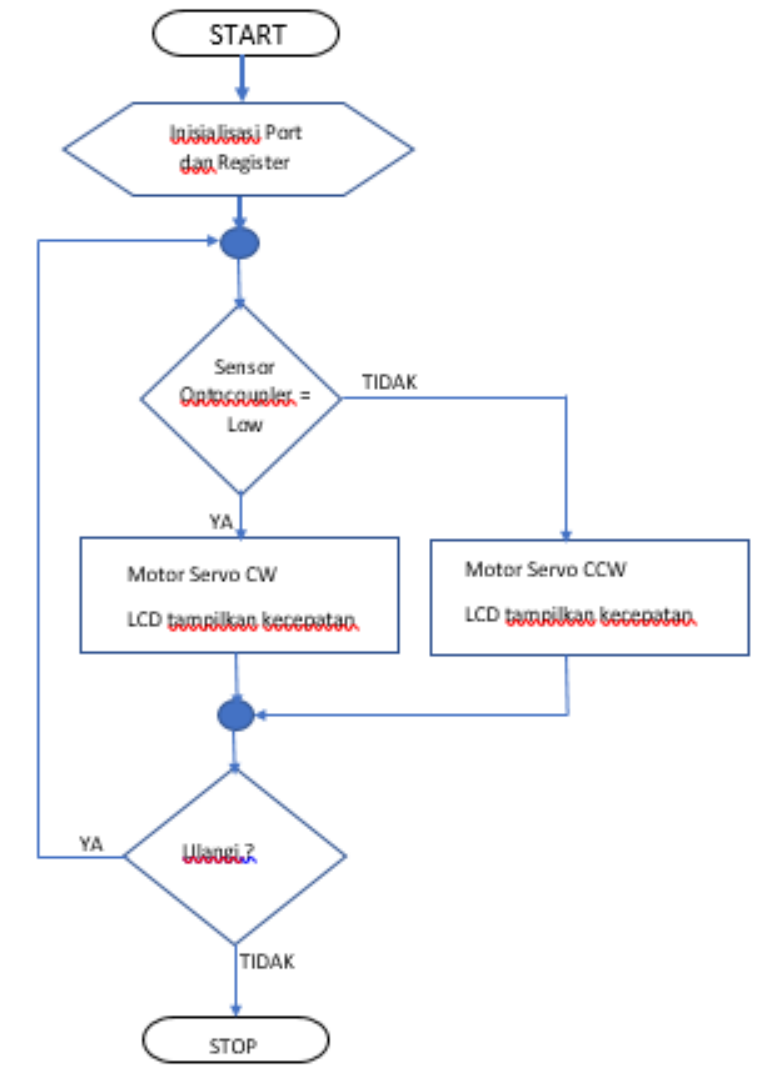

\section{Pengujian Sistem}

Gambar 5 Flowchart

Pengujian sistem ini dapat dilakukan mulai dari pengujian alat permodul sampai pengujian alat secara keseluruhan. Langkah-langkah dalam pengujian alat tersebut adalah sebagai berikut :

\section{Pengujian Tegangan Sensor Optocoupler}

Pengujian tegangan keluaran sensor optocoupler perlu dilakukan sebagai indikasi nilai pembacaan yang akan di lakukan, nilai awal untuk pembacaan optocoupler dapat dilihat pada tabel dibawah ini.

Tabel 1 Hasil pengujian Tegangan Sensor Optcoupler

\begin{tabular}{|l|l|}
\hline \multicolumn{1}{|c|}{ Keadaan Sensor } & Tegangan Output Sensor \\
\hline Terhalang & $5 \mathrm{~V}$ \\
\hline Tak Terhalang & $0,13 \mathrm{~V}$ \\
\hline
\end{tabular}


Pada tabel tersbut bahwa ketika sensor tidak terhalang nilai yang dikeluarkan adalah $0,13 \mathrm{~V}$ yang menandakan nilai berlogika $\mathrm{LOW}(0)$ dan $5 \mathrm{~V}$ menandakan nilai berlogika $\mathrm{HIGH}(1)$ kondisi sensor terhalang.

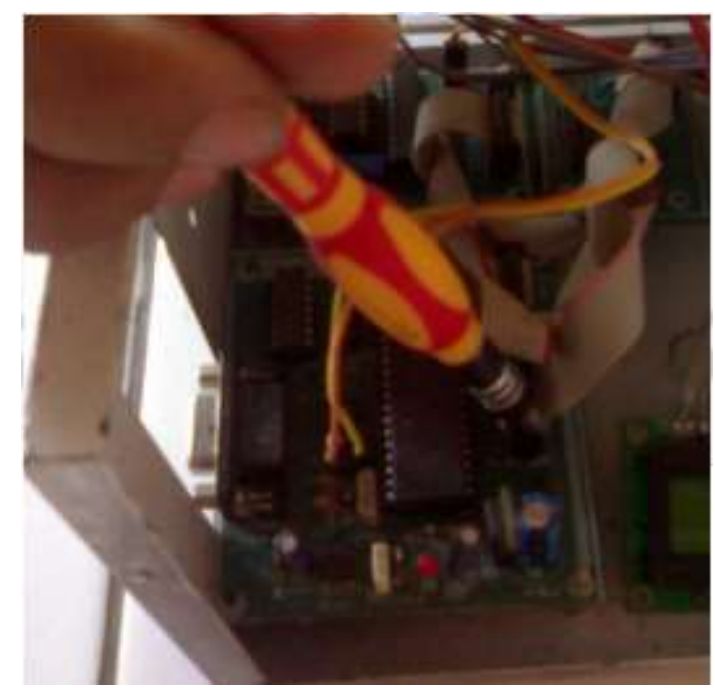

Gambar 6 Pengujian Tegangan Sensor Optocoupler

\section{Pengujian Motor Servo}

Pada gambar dibawah ini, posisi motor servo tidak kelihatan, disini motor servo berperan untuk menaikkan dan menurunkan turbin (pipa berwarna putih) apabila debit airnya rendahkan maka motor servo akan berputar $\mathrm{CW}$ jika debitnya tinggi maka motor dc akan berputar $\mathrm{CCW}$

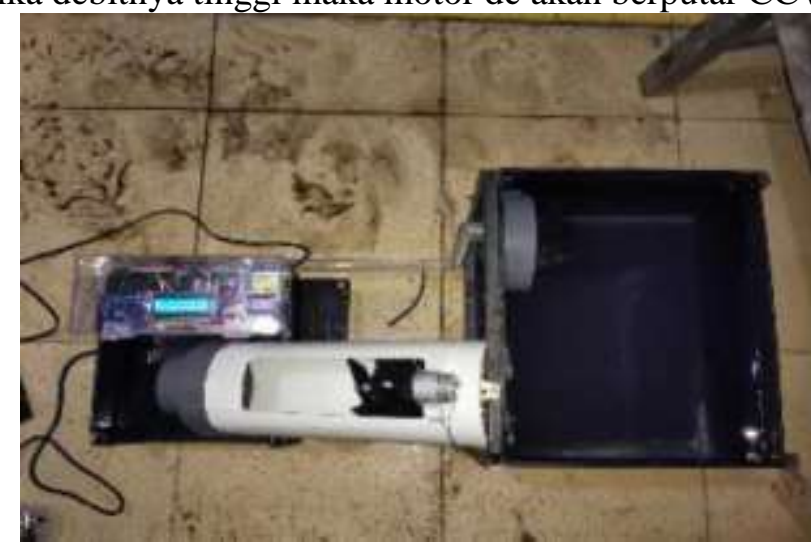

Gambar 7 Pengujian Motor Servo

\section{Pengujian LCD 2x16}

Dapat dilihat pada gambar bahwa LCD dapat menampilkan kecepatan air berdasarkan input dari sensor optocoupler 


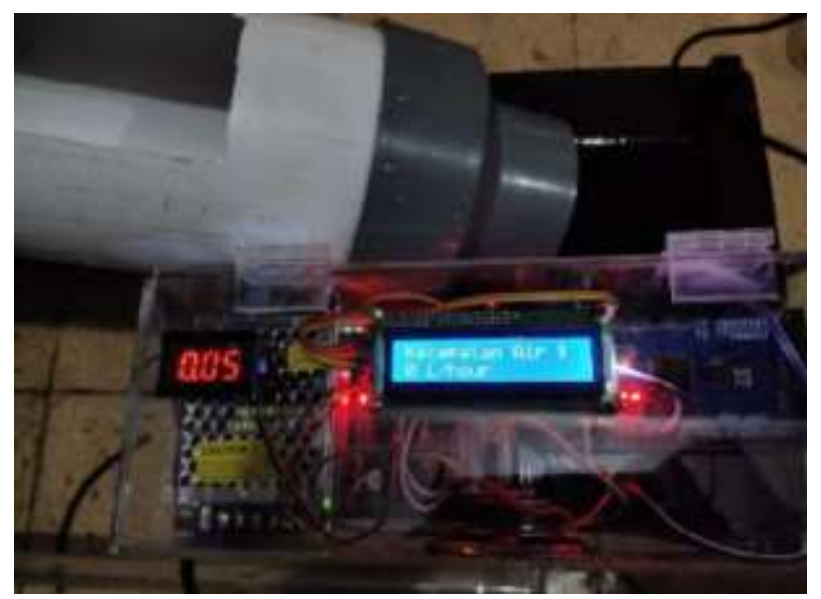

Gambar 8 Pengujian Lcd

\section{Kesimpulan}

Berdasarkan hasil pengujian pada bab-bab sebelumnya, maka dapat diambil kesimpulan sebagai berikut : Sensor optocoupler bisa membaca kecepatan putaran motor sehingga sudut kemiringan turbin dapat ditentukan. Motor servo dapat dikendalikan sesuai input yang diberikan berdasarkan pembacaan sensor optocoupler, LCD 2x16 dapat memberikan informasi kecepatan putaran motor yang menandakan jumlah debit air.

\section{DAFTAR PUSTAKA}

[1] (Cekmas Cekdin, 2017. Sistem Teknik Kendali)

[2] (Heri Andrianto, Aan Darmawan, Arduino Belajar Cepat dan Pemograman, 2016)

[3] (Kadir Abdul, Pemrograman Arduino Menggunakan ArduBlock, 2017)

[4] Kadir, Abdul. 2015. Arduino Dan Sensor Tuntunan Praktis Mempelajari Penggunaan Sensor Untuk Aneka Proyek elektronika Berbasis Arduino. Yogyakarta: AndiOffset..

[5] (Marta Yuwono Dinata, Arduino Itu Pintar, 2016) 